\title{
Use of Fireproofing Compositions in Order to Prevent Forest Fires
}

\section{Olga A. IVCHENKO}

Postgraduate student

Saratov State Vavilov Agrarian University named after N.I. Vavilov

1, Teatralnaya Ploshad, Saratov, 410012, Russia

\section{Kirill E. PANKIN}

Ph.D. (in Chemical Sciences)

Associate Professor

Saratov State Vavilov Agrarian University named after N.I. Vavilov

1, Teatralnaya Ploshad, Saratov, 410012, Russia

\section{Galina P. NADEZHKINA}

Ph.D. (in Engineering Sciences)

Associate Professor

Saratov State Vavilov Agrarian University named after N.I. Vavilov

1, Teatralnaya Ploshad, Saratov, 410012, Russia

\section{Olga G. UDALOVA}

Ph.D. (in Agricultural Sciences)

Associate Professor

Saratov State Vavilov Agrarian University named after N.I. Vavilov

1, Teatralnaya Ploshad, Saratov, 410012, Russia

\section{Dmitriy A. RYBALKIN}

Ph.D. (in Engineering Sciences)

Associate Professor

Saratov State Vavilov Agrarian University named after N.I. Vavilov

1, Teatralnaya Ploshad, Saratov, 410012, Russia

\begin{abstract}
The fight against low forest fires includes three activities: (1) preventing the occurrence, (2) limiting the spread and finally, if the first two have not helped, (3) extinguishing the fire edge. It is impossible to completely eliminate the factors that contribute to the emergence and development of
\end{abstract}


fires in these areas, so the most effective measures will be to prevent the free flow of fire. The article suggests a way to prevent and limit the spread of low fire by creating fire protection strips areas covered with grass cover and plant residues, treated (sprayed) with water solutions of aluminum hydroxide gel. The effectiveness of fire barrier properties of such strips has been investigated experimentally during field experiments. It is shown that obvious signs of fireproof action of aluminum hydrogel begin to appear at its concentration from $7 \mathrm{~g} / \mathrm{l}$, at the flow rate of 1 liter of solution per $1 \mathrm{~m}^{2}$ of the area of the treated area. In this case, the grassroots fire loses its stability and its speed decreases by 2-3 times. Treatment of sites with hydrogel solutions with a concentration of $14 \mathrm{~g} / \mathrm{l}$ or more completely prevented the spread of the flame over the area of the grass cover, in addition, attempts to force burning the site $(28 \mathrm{~g} / \mathrm{l})$ were unsuccessful. Water-soluble boron - boron - with concentrations of 14-56 g/l does not have sufficient flame retardant effect to stop the spread of low fires.

Keywords: forest fires; ground fires; fire-protective barriers; prevention of forest ground fires; aluminum hydroxide gel.

\section{Introduction}

Forests play an enormous role in water and land conservation, environmental improvement and agriculture. The importance of the forest as a natural ecological potential is particularly great because of its ability to regenerate. The forest restores and stabilizes the ecological balance in nature and can be used to protect and improve the environment. But its resources are not limitless in conditions of urbanization, industrial pollution the forest loses or weakens its protective functions, forest censuses lose their sustainability under the impact of climate change and increasing human pressure (Ivanov \& Evdokimenko, 2017; Furyaev et al., 2017; Tsvetkov, 2017). Forests account for only $8 \%$ of the natural landscape, but have an incredible mass of organic matter, enormous energy, huge internal surface and intensity of the biological cycle, forest is much stronger than other types of vegetation affects energy and mass exchange in the biosphere, its functioning, the formation of the natural environment, the transformation of climatic, geochemical and other factors (Kotelnikov et al., 2017).

One of the most important modern problems is the reduction of forest-covered areas, one of the main roles in which forest fires play. There are the following consequences of fires: biocenosis species diversity is being transformed, there is a risk of complete disappearance of rare tree species in these regions; soil composition and water regime are being changed; the cycle of carbon and nitrogen compounds is being changed locally; agricultural activity is being disturbed, because 
smoke hinders the full process of photosynthesis, which hinders growth and maturation of crops; there is a need for unforeseen financial expenses for restoration of damaged areas.

A forest ground fire has clear and implicit consequences. The obvious consequences include the loss of commercial timber and non-timber forest products, such consequences can be easily assessed economically and measures to address them developed. Implicit consequences include release of carbon stocks into the atmosphere, loss of ecological and agroforestry functions of the forest, post-fire spread of plant diseases, reproduction and spread of insects-pests, difficulty (or impossibility) of reforestation due to serious damage to the soil layer, etc. It is very difficult to estimate the danger and economic damage from implicit consequences, as they manifest themselves in the postponed perspective - many years after a fire. Therefore, it is economically more profitable to prevent forest fires by organizing the rational exploitation of its resources and by carrying out fire prevention measures.

Nevertheless, even rational forest exploitation implies serious anthropogenic load, as to ensure economic efficiency it is necessary to set a certain pace of work. Different methods are used to fight forest fires. In order to limit the spread of ground forest fires, the soil cover is mineralized, i.e. forest combustible materials (herbaceous plants, forest residue, deadwood, etc.) are removed from soil, as all this is a "nutrient medium" for the growth and spread of forest ground fires. Special ploughs (PCL series) and powerful energy-saturated wheeled or tracked vehicles are used to ensure high productivity in this process. Fire ploughing leads to disturbance of the soil cover due to the complex influence of the soil tillage organ and wheel or caterpillar motions. Often another method is used - controlled annealing of the territory, which is less labor and financial costs, but is dangerous, because it can also cause another fire. In connection with the above mentioned purpose of this work is to develop a technology of creating a fire barrier that combines high efficiency and minimum labor and financial costs, which consists in processing a layer of forest combustible materials with flame retardant compositions based on aluminum and boron compounds and experimental testing their fire retardant properties.

To reduce the flammable properties of combustible building materials (construction timber, plastic masses, composites, etc.) they are processed (or added to them) by special substances - fire suppression materials (or flame retardants). According to literature data, the highest flame retardant ability is shown by aluminum, boron, magnesium, nitrogen, phosphorus, etc. compounds (Kutnar, Muthu, 2016; Gaff et al., 2019; Giudice, 2017; Sut et al., 2016; Uddin et al., 2020). The choice of these compounds is conditioned by absence of toxic influence on growth and development of plants: aluminum is component of mineral skeleton of soil - aluminosilicates, boron together with calcium influences formation of walls of plant cells. 


\section{Methods}

Field experiments were conducted in August - September 2019 in Saratov region in the steppe area on the most fire-hazardous areas of herbs. Dust formation was observed in open areas at gusts of wind, which indirectly indicates the extreme state of drying of the top layer of soil (precipitation, in the form of rain, in this area was not observed during the previous 30 days). Air humidity was 23-26 $\%$, air temperature was $26-30^{\circ} \mathrm{C}$, air pressure was close to normal (760 mm Hg), wind speed depending on the time of day varied from full dull to 4-6 m/s. Air temperature, humidity and wind speed were measured with the help of Meteoscope-M (LLC "NTM-Zaschita", Russia). The humidity of the soil was determined indirectly by digging a $0.5 \mathrm{~m}$ deep drill and a soil sample taken from that depth turned into fine dust when rubbing between fingers.

As the grass fire is able to move from one forest area to another through the grass cover and a layer of forest combustible materials, the soil areas inhabited by different herbs were chosen as experimental ones. To ensure sustainable combustion and to form conditions close to those of a sustainable low fire, areas with uniform grass with a height of $30-50 \mathrm{~cm}$ were selected. In order to comply with fire safety rules, all sections were opaque, i.e. a mineralized strip of at least $1.5 \mathrm{~m}$ wide was created along the perimeter of all sections. Processing sectors of 1 and $4 \mathrm{~m}^{2}$ in area (1x $1 \mathrm{~m}$ and $2 \times 2 \mathrm{~m}$ ) were formed inside the site, to distinguish these zones the boundaries of the treated areas were marked with pegs, between which synthetic threads were stretched.

Aluminium hydroxide gel was chosen as a flame retardant, which was obtained by dissolving the aluminium sulfate in water (tap water). This method is easy to use and requires only two components: a certain weight of aluminum sulfate (easily soluble in water) and the required amount of water. When these components are mixed, aluminium hydroxide gel formation follows the following diagram:

$$
\mathrm{Al}_{2}\left(\mathrm{SO}_{4}\right)_{3}+6 \mathrm{H}_{2} \mathrm{O}=2 \mathrm{Al}(\mathrm{OH})_{3} \downarrow+3 \mathrm{H}_{2} \mathrm{SO}_{4}
$$

The formation of crystal aluminum hydroxide goes through the stage of formation of colloidal solution - aluminium hydroxide gel. The colloidal solution is not stable in time and is gradually destroyed, forming a crystalline aluminium hydroxide. The hanger was chosen in such a way as to obtain a minimum concentration of aluminium hydroxide gel at an acceptable extinguishing efficiency in a certain range from 1.7 to $28 \mathrm{~g} / \mathrm{l}$. The choice of aluminum hydrogel concentration was based on the results of work (Ivchenko, Pankin, 2019). As a boron compound was chosen a borax is a sodium tetraborate $\left(\mathrm{Na}_{2} \mathrm{~B}_{4} \mathrm{O}_{7}\right)$ - a water-soluble substance giving stable aqueous solutions in time. The solution was hinged in such a way that the concentrations of 3.5-13 g/l were obtained and dissolved also in the corresponding volume of tap water. 
Areas were treated with a garden sprayer type "Beetle" OP-209 with a flow rate of 0.6-0.8 1/min. For the convenience of treatment of experimental sites the flow rate of solutions was $11 \cdot \mathrm{m}^{-2}$. Areas were sprayed according to the following scheme. First, areas with high concentrations of aluminium hydroxide gel $\left(28 \mathrm{~g} \cdot \mathrm{l}^{-1}\right)$ and drills $\left(56 \mathrm{~g} \cdot \mathrm{l}^{-1}\right)$ were sprayed, and then more diluted solutions were used. To detect the effect of humidity in addition to the control area (not treated), one of the areas was treated with tap water without any additives with the same flow rate $\left(11 \cdot \mathrm{m}^{-2}\right)$, and this area was treated last. After the treatment, the experimental sites were dried for hour and also for 12 hours (i.e. until the next day).

Areas of the grass cover were set on fire in the direction of the wind with the help of a forest incendiary device "Ermak" (Russia). The spillage of burning fluid was carried out on the part of the grass cover, which was not treated (ignition zone) and was in front of experimental sectors (Figure 1). The combustion development was carried out for 10-20 seconds. - sufficient time, under the given conditions, for the formation of sustainable combustion of the grass cover and formation of the fire edge. In some cases, to enhance combustion, dry straw was added to the ignition sector at the rate of $200-250 \mathrm{~g} \cdot \mathrm{m}^{-2}$. For revealing of ability (or inability) of sites (fireproof strip) processed by fireproof compositions to resist distribution of low fire two types of experiments were conducted: (1) with frontal movement of the flame - the experimental sectors were located across the direction of the edge of the low fire and (2) with flank movement of the flame, in this case the experimental sectors were located along the direction of the flame. Such principle of carrying out of field experiment should show presence of influence of fire-protective composition on speed of propagation of edge of low fire and presence of basic overcoming of such fire-protective barrier under certain conditions of external environment. It is necessary to note, that at carrying out of the experiment of the second type successive increase in concentration of a solution of fireproof structure was carried out to reveal possible changes of character of burning in process of movement of a fire edge on untreated and processed sites, and also a possible place of a stop of a flame.

\begin{tabular}{cccccccc}
$\begin{array}{cccc}\text { Sector 1 } \\
14 \mathrm{~g} \cdot 1^{-1}\end{array}$ & $\begin{array}{c}\text { Sector 2 } \\
21 \mathrm{~g} \cdot \mathrm{l}^{-1}\end{array}$ & $\begin{array}{c}\text { Sector 3 } \\
28 \mathrm{~g} \cdot 1^{-1}\end{array}$ & $\begin{array}{c}\text { Sector 4 } \\
\text { Water }\end{array}$ & $\begin{array}{c}\text { Sector 5 } \\
\text { (without } \\
\text { fireproofing } \\
\text { compositions) }\end{array}$ & $\begin{array}{c}\text { Sector 6 } \\
7 \mathrm{~g} \cdot 1^{-1}\end{array}$ & $\begin{array}{c}\text { Sector 7 } \\
1.7 \mathrm{~g} \cdot 1^{-1}\end{array}$ & $\begin{array}{c}\text { Sector 8 } \\
3.5 \mathrm{~g} \cdot \mathrm{l}^{-1}\end{array}$ \\
\hline \multicolumn{7}{c}{$\uparrow$ Ignition zone $\uparrow$} \\
\hline
\end{tabular}

\section{Figure 1. Location plan of experimental sectors under front movement of ground fire. The arrows indicate the direction of movement of the ground fire edge}

\section{Results}

In order to assess forest combustible materials reserves at the experimental sites, a study of combustible materials, density and species composition, grass cover and plant remains was 
conducted. Species composition of vegetation: $80 \%$ - creeping wheatgrass, $20 \%$ - sage, wormwood, cornflower, alfalfa etc. The mass distribution of combustible materials on the area of experimental sectors was, on average, $0.7-1.1 \mathrm{~kg} \cdot \mathrm{m}^{-2}$.

Researches of fireproof and fireproof properties at front distribution of a flame of bottom fire have shown, that the experimental sectors processed by fireproof compositions on the basis of aluminium hydroxide gel with concentration $14-28 \mathrm{~g} \cdot \mathrm{l}^{-1}$ at the expense of $1 \mathrm{l} \cdot \mathrm{m}^{-2}$ possess exactly fireproof properties. The area of each sector was $1 \times 1 \mathrm{~m}^{2}$. Scheme of the experiment is shown in Figure 1. As can be seen from the figure presented experimental sectors are scattered in random order to exclude the effect of the cumulative effect of fireproof material on the spread of the edge of the low fire. Drying time of sections was - 1 hour (due to possible change of wind direction in the next experimental day). The results are presented in Figures 2 and 3.

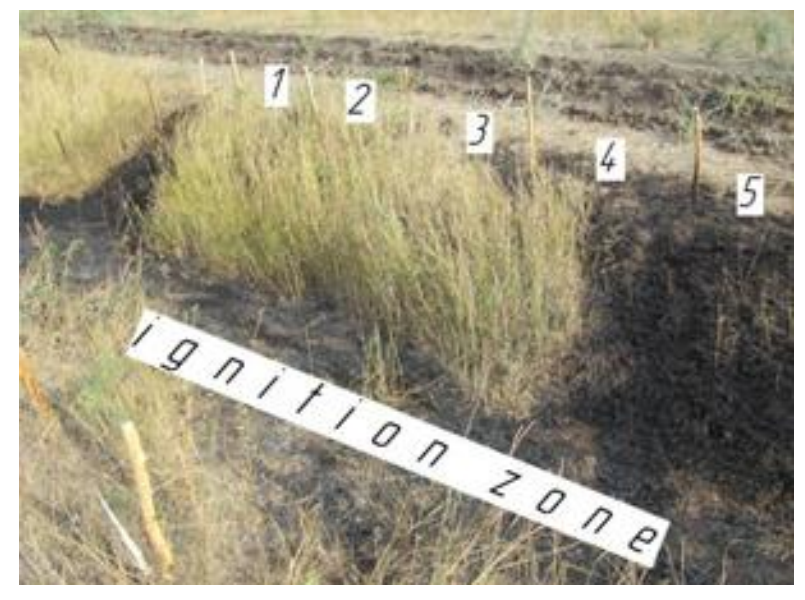

Figure 2. Results of fire-retardant

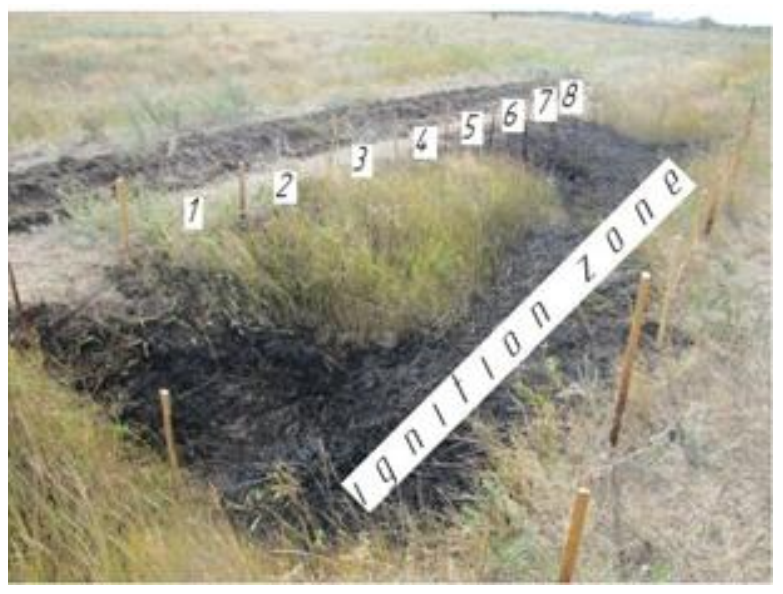

Figure 3. Results of fire-retardant

\section{characteristics of experimental sectors which characteristics of experimental sectors which were treated with aluminum hydroxide gel - were treated with aluminum hydroxide gel - photo of the area on the left photo of the area on the right}

The presented photos (Figures 2 and 3) show that after the fire experiment three experimental sectors No. 1-3 treated aluminium hydroxide gel with concentrations of 14,21 and $28 \mathrm{~g} \cdot \mathrm{l}^{-1}$, respectively, showed fire retarding properties, while the other sectors were unable to contain the spread of the edge of the model low fire.

Inspection of fire-resistant sectors showed that under the prevailing weather conditions (wind 4-6 $\mathrm{m} / \mathrm{s}$ ) a strip of grass cover $1 \mathrm{~m}$ wide was praised to contain the spread of the edge of the low fire. It is interesting to note that fire-resistant experimental sectors were burned only along the edges and had to bypass fire-resistant sectors to the right and left to continue their movement (Figures 2 and 3). The reason of increase of fire resistance of experimental sectors is in their 
treatment by aluminium hydroxide gel solutions with corresponding concentrations, which turned out to be able to reduce fire dangerous properties of forest combustible materials to such level, that it turned out to be sufficient for stopping the spread of low fire flame. The proof of this is the complete burnout of the control area - Sector 5 (not treated). The influence of humidity in the areas can also be excluded, because Sector 4 (treated with water) was also unable to contain the spread of the flame. Besides, all other things being equal, Sector No. 4 was more humid, because it was treated (sprayed with water) with the last of the experimental sectors treatment series. It is also interesting to note that the flame propagation in Sector No. 6 (aluminium hydroxide $\mathrm{gel}, 7 \mathrm{~g} \cdot \mathrm{l}^{-1}$ ) has acquired a distinctly fluent character - only the grass cover has been burned out and the frozen plant remains on the surface have not been exposed to the flame.

The possibility of using boron compounds to built fire protection barriers has not been discussed in scientific and technical literature before. Therefore, for the convenience of comparison, fireprotective properties of borax and aluminium hydroxide gel range of concentrations of water solutions of borax was chosen similar, ie 7-28 g. $\mathrm{l}^{-1}$. Processed sectors could not hold the front of low fire spread, however, the inspection of sectors after the experiment revealed the presence of a fluent nature of fire edge spread.

\section{Discussion}

To confirm the obtained results of the fire-protective action of aluminium hydroxide gel, the experiment with the front flame spread was transformed into the flank spread of the low fire edge (the fire edge spreads along the experimental sectors). The locations of the experimental sectors at flank flame propagation are shown in Figure 4. As can be seen, the location of the sectors was carried out with a sequential increase in concentration. For exclusion of influence of humidity in this type of experiment the drying of site aluminium hydroxide gel was carried out within 12 hours (fire experiment was carried out on next day). Dry straw in the amount of $150-200 \mathrm{~g} \cdot \mathrm{m}^{-2}$ was added to the ignition area to enhance combustion. Figures 5 and 6 present the results of experimental study of fire-retardant characteristics of sectors treated with different concentrations of aluminium hydroxide gel.

\begin{tabular}{|c|c|c|}
\hline$\rightarrow$ & Sector №1 & Sector №2 \\
$\left(21 \mathrm{~g} \cdot \mathrm{l}^{-1}\right)$ & $\left(28 \mathrm{~g} \cdot \mathrm{l}^{-1}\right)$ \\
& & \\
\hline
\end{tabular}

Figure 4. Location of experimental sectors which were treated with aluminum hydroxide gel under flank dispersion of ground fire. The arrows indicate the direction of flame dispersion. 


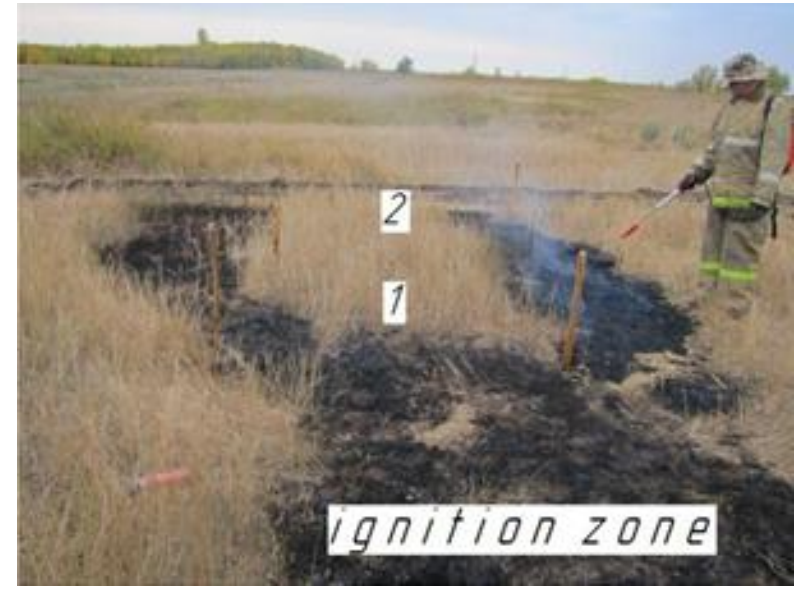

Figure 5. Experiment with flank flame dispersion - look at experimental sectors from ignition zone

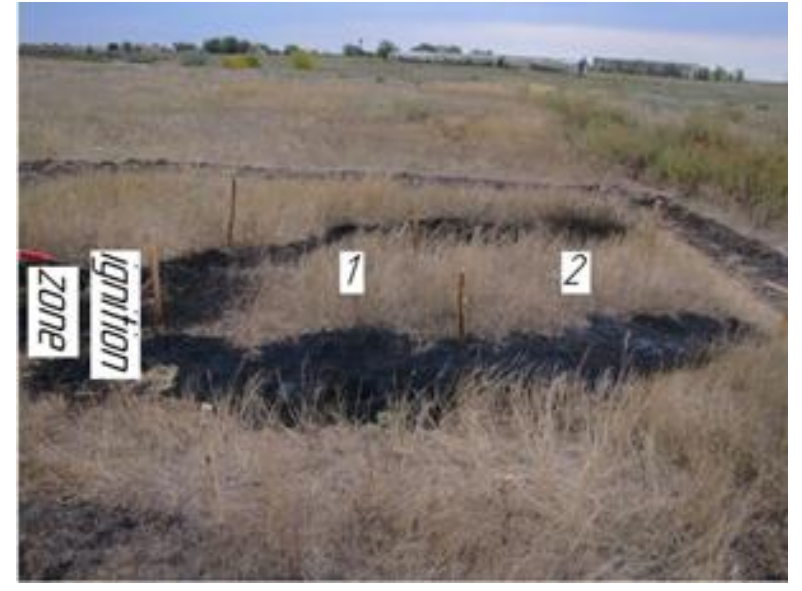

Figure 6. Experiment with flank flame dispersion - look at experimental sectors from right side

Inspection of the experimental sectros showed that, as in the course of the experiment with frontal flame propagation, in this case Sector No. 5 (aluminium hydroxide gel, $14 \mathrm{~g} \cdot \mathrm{l}^{-1}$ ) held back the propagation of the flame of the low fire. The treated grass cover in Sector 6 (aluminium hydroxide gel, $28 \mathrm{~g} \cdot \mathrm{l}^{-1}$ ) was burned only along the edges because of the longitudinal movement of the edge of the low fire, which moved along the experimental section through Sectors 1-3. In Figure 5, it is clearly seen that the edge of the low fire bypassed the areas treated with aluminium hydroxide gel with concentrations of 14 and $28 \mathrm{~g} \cdot \mathrm{l}^{-1}$, respectively. It is interesting to note, that at movement of the edge of fire through Sector №4 (aluminium hydroxide gel, $7 \mathrm{~g} \cdot \mathrm{l}^{-1}$ ) the fire has lost its stability (Figure 6) and has passed in a fluent mode of distribution and then has lost its force at achievement of Sector №5 (aluminium hydroxide gel, $14 \mathrm{~g} \cdot \mathrm{l}^{-1}$ ). In their turn, Sectors 1-3 have burned out completely, thus, the treatment of sites with water, as well as with fire protection compositions based on aluminium hydroxide gel with concentrations of $1.7,3.5$ and $7 \mathrm{~g} \cdot \mathrm{l}^{-1}$, respectively, does not allow the grass cover and dead plant residues to withstand the spread of the flame and such sites can not act as fire retaining strips. The study of Sectors No. 1-4 showed that only in Sector No. 4 (aluminium hydroxide gel, $7 \mathrm{~g} \cdot \mathrm{l}^{-1}$ ) only the grass cover burned out and the plant remains on the soil surface only partially burned out. We observed a similar result in an experiment with frontal flame propagation. What could be the reason for this flame propagation regime? It is known that herbaceous plants, at this period of time, are in an extreme state of drying, with the surface of their leaf plates and stems becoming hydrophobic and insufficiently wet with water and water solutions. Because of this, it seems that most of the water solution of the flame retardant composition is simply spilled on the dead plant residues located on the surface of the soil the liquid is spilled from vertical to horizontal surfaces. It is quite probable that the same properties of the borax (its high water solubility) do not allow it to hold on the leaves and stems of herbaceous 
plants in the required amount and during the spraying all the flame retardant composition flows off the leaves and stems from them concentrates on plant residues without showing any fire retardant effect. The similar effect, inefficient use of water at extinguishing forest fires because of the reduced wettability of forest combustible materials water is known, that is why forest firefighters use as additives to water - wetting agents - surface-active substances, improving this index (Richter, 2014). As a result, the flame retardant composition is concentrated on plant residues and therefore they are only partially exposed to the flame. Proof of this hypothesis is a more complete burnout of grass cover and plant residues on areas treated with water or aluminium hydroxide gel with concentrations of 1.7-3.5 $\mathrm{g} \cdot \mathrm{l}^{-1}$ and on control areas that have not been treated, as well as on ignition sectors.

\section{Conclusion}

It is quite possible that the sectors treated with aluminium hydroxide gel have shown their fire resistance for reasons completely unrelated to the fire protection effect of the aluminum compound. It is possible that any other causes uncontrolled during the experiment caused the flame to bypass the treated aluminium hydroxide gel areas. Therefore, in order to test the fire resistance of the site, an additional experiment was carried out with an attempt of forced burning of forest combustible materials in sectors that showed fire resistance. To check the fire resistance, 150-200 g of dry straw was placed in separate zones of the experimental sector and burned. A fire was set in three locations in the pilot sector. It should be noted that in this experiment, straw and grass cover were fired using a gas burner (propane-butane mixture), i.e., without oil products. This was done in order to comply with the conditions for the natural spread of natural grass fires, which are carried out without the use of oil products.

The inspection of the places where the grass cover in the fire-resistant sector is forced to be fired showed that burning dry straw leads to its burning, as well as burning of the part of the grass cover of the sector that has been caught in the fire zone. As the straw burns out, spontaneous combustion ends and no further flame spreads over the area, despite favorable weather conditions and the presence of a sufficiently powerful ignition source. Thus, in the course of the conducted experiment one more interesting property of a fireproof strip - suppression of burning of an ignition source which has got on its territory was found out. Due to the reduction of fire hazardous properties of forest combustible materials, the ignition source that got on the strip of burning will be able to ignite only the grass cover, which is directly adjacent to the burning zone, itself, treated with a fire retardant composition, the grass cover in the process of independent combustion is not involved and does not contribute to the spread of the edge of the low fire. 


\section{References}

Furyaev, V.V., Tsvetkov, P.A., Furyaev, I.V., Zlobina, L.P. (2017). Forest fire and forest economic prerequisites for improved protection in forest areas of the Krasnoyarsk Krai. Siberian Journal of Forestry, 5, 55-62. (in Russian)

Gaff, M., Kacik, F., Gasparik, M., Todaro, L., Cekovska, H. (2019). The effect of synthetic and natural fire-retardants on burning and chemical characteristics of thermally modified teak (Tectona grandis L. f.) wood. Construction and Building Materials, 200, 551-558. https://doi.org/10.1016/j.conbuildmat.2018.12.106

Giudice, C. (2017). New Technologies in Protective Coatings. Inopentech.

Ivanov, V.V., Evdokimenko, M.D. (2017). The role of logging and fires in the of forest dynamics of Baikal basin. Sylviculture, 4, 256-269. (in Russian)

Ivchenko, O.A., Pankin, K.E. (2019). Quenching of forest combustible materials with hydrogels based on aluminum hydroxide. Forestry Engineering Journal, 33(1), 76-84. (in Russian)

Kotelnikov, R.V., Korshunov, N.A., Giryaev, N.M. (2017). Decision-making tasks in the field of fire protection of forests are the main priorities of information support development. Siberian Journal of Forestry, 5, 18-24. (in Russian)

Kutnar, A., Muthu, S.S. (2016). Environmental Impacts of Traditional and Innovative Forest-based Bioproducts. Springer.

Richter, T.E. (2014). Ground Cover Fire Fighting for Structural Firefighters. Fire protection publication, Oklahoma State University.

Sut, A., Greiser, S., Jäger, C., Schartel, B. (2016). Aluminium diethylphosphinate versus ammonium polyphosphate: Acomprehensive comparison of the chemical interactions duringpyrolysis in flame-retarded polyolefine/poly(phenylene oxide). Thermochimica Acta, 640, 74-84. https://doi.org/10.1016/j.tca.2016.08.004

Tsvetkov, P.A. (2017). Pyrology in Russia: achievements and problems. Siberian Journal of Forestry, 5, 6-17. (in Russian)

Uddin, M., Kiviranta, K., Suvanto, S., Alvila, L., Haapala, A. (2020). Casein-magnesium composite as an intumescent fire retardant coating for wood. Fire Safety Journal, 112, 102943. https://doi.org/10.1016/j.firesaf.2019.102943 